\title{
Polymerization time for a microwave-cured acrylic resin with multiple flasks
}

\section{Tempo de polimerização de resina acrílica em microondas, utilizando múltiplas muflas}

\author{
Daniela Maffei Botega* \\ Tatiana de Souza Machado** \\ José Antônio Nunes de Mello*** \\ Renata Cunha Matheus Rodrigues Garcia**** \\ Altair Antoninha Del Bel Cury*****
}

\begin{abstract}
This study aimed at establishing the polymerization time of a microwave-cured acrylic resin (Acron ${ }^{\mathrm{TM}}$ $\mathrm{MC}$ ), simultaneously processing 2, 4, and 6 flasks. Required time was measured according to the parameters: monomer release in water, Knoop hardness, and porosity. Samples were made with Acron ${ }^{\mathrm{TM}} \mathrm{MC}$ in different shapes: rectangular $(32 \times 10 \times 2.5 \mathrm{~mm})$ for monomer release and porosity; and half-disc $(30 \mathrm{~mm}$ in diameter $\times 4 \mathrm{~mm}$ in height) for Knoop hardness. There were four experimental groups ( $n=24$ per group): G1) one flask (control); G2) two flasks; G3) four flasks, and G4) six flasks. At first, polymerization protocol was similar for all groups ( $3 \mathrm{~min} / 450 \mathrm{~W})$. Time was then adjusted for G2, G3, and G4, based on monomer release evaluation in the control group, obtained by spectrophotometer Beckman DU-70, with emitting wave of $206 \mathrm{~nm}$. Knoop hardness test was performed using a Shimadzu HMV 2000 hardness tester, and 10 indentations were performed on each specimen's surface. Porosity was assessed after specimens were immersed in black ink and the pores counted in a microscope. Results showed that the complete polymerization of the resin occurred in 4.5 min for two flasks (G2); 8.5 min for four flasks (G3); and 13 min for six flasks (G4), all with $450 \mathrm{~W}$. Statistical analysis revealed that the number of flasks does not interfere with polymerization, Knoop hardness, and porosity of the resin. Results showed that polymerization of microwave-curing resin with more than one flask is a viable procedure, as long as polymerization time is adjusted.
\end{abstract}

DESCRIPTORS: Acrylic resins; Microwaves; Polymers; Porosity.

\begin{abstract}
RESUMO: O objetivo deste estudo foi o de determinar os tempos necessários para a polimerização padrão de uma resina acrilica em microondas, utilizando várias muflas simultaneamente. Os tempos necessários foram aferidos por parâmetros como monômeros liberados em água, dureza Knoop e porosidade. As amostras, confeccionadas em resina Acron ${ }^{\mathrm{TM}} \mathrm{MC}$, apresentavam as seguintes dimensões: para os parâmetros monômero residual e porosidade, retângulos de $32 \times 10$ × 2,5 mm e, para dureza superficial Knoop, semidiscos de 30,0 mm de diâmetro e 4,0 mm de espessura. As mensurações foram realizadas em quatro grupos ( 24 amostras cada): G1 - uma mufla (controle); G2 - duas muflas; G3 - quatro muflas; e G4 - seis muflas no forno de microondas, respectivamente. Inicialmente, o mesmo protocolo de polimerização foi utilizado para todos os grupos: 3 minutos a $450 \mathrm{~W}$. Em seguida, o tempo de polimerização foi ajustado para os grupos 2, 3 e 4, usando como padrão os resultados do grupo 1 obtidos na análise do monômero liberado em água em espectrofotômetro Beckman DU-70, com comprimento de onda de 206 nm. Para a determinação da dureza Knoop, 10 endentações foram realizadas em cada espécime, utilizando microdurômetro Shimadzu HMV-2000. A porosidade foi avaliada após a imersão das amostras em tinta nanquim preta, contando-se os poros em microscópio. Os tempos necessários para a polimerização da resina Acron ${ }^{\mathrm{TM}} \mathrm{MC}$ foram: 4,5 minutos para duas muflas; 8,5 minutos para quatro muflas e 13 minutos para seis muflas. De acordo com os resultados, a polimerização de resina em microondas, utilizando mais de uma mufla no forno, é um procedimento viável, desde que os tempos de polimerização sejam ajustados.
\end{abstract}

DESCRITORES: Resinas acrilicas; Microondas; Polímeros; Porosidade.

\section{INTRODUCTION}

Polymerization of acrylic resins can be accomplished by chemical activation, visible light activation or heating activation using hot water or microwave energy ${ }^{2}$. In the latter method, the monomer molecules vibrate by being exposed to a high-frequency electromagnetic field. This phe-

\footnotetext{
* Graduate Student; **DSc Student; ****PhD; *****Professor - Department of Prosthodontics and Periodontology, School of

Dentistry of Piracicaba, State University of Campinas.

$* * * \mathrm{PhD}$, Department of Dentistry, Federal University of Amazonas.
} 
Botega DM, Machado TS, Nunes de Mello JA, Rodrigues Garcia RCM, Del Bel Cury AA. Polymerization time for a microwave-cured acrylic resin with multiple flasks. Braz Oral Res 2004;18(1):23-8.

nomenon leads to intermolecular collisions that generate the heat for the activation process ${ }^{4}$.

An acceptable acrylic polymerization method is one capable of achieving the best properties of the acrylic resin, e.g., hardness, porosity, and monomer release. It has been shown that high levels of residual monomer is cytotoxic in denture base resin ${ }^{17}$ and adversely affect acrylic resin properties, such as hardness and porosity ${ }^{6,8,10}$. Many authors concluded that monomer release and other properties are similar in both techniques: microwave energy or hot water $1,6,7,9,12,13$. The microwave energy employed to polymerize acrylic resins has been encouraged due to the less cumbersome equipment, cleanness of the method, and acceptable properties ${ }^{3,9,12,13,16}$. Although the curing time is already recognized as short, inserting various flasks simultaneously in the microwave oven could save additional laboratory time ${ }^{6}$. However, at this time, few studies have been carried out considering the possible effects of this approach in the properties of the acrylic resin dough.

Based on the existing literature, the aim of this study was to establish the necessary polymerization time of a microwave-cured acrylic resin for simultaneous processing of 2, 4, and 6 flasks, assessing monomer release, Knoop hardness, and porosity.

\section{MATERIAL AND METHODS Pattern and mold preparation}

Rectangular silicone patterns $(32 \times 10 \times$ $2.5 \mathrm{~mm}$ ) were made for monomer release and porosity analyses, while half-disc shaped silicone patterns of $30.0 \mathrm{~mm}$ in diameter and $4.0 \mathrm{~mm}$ in height were used for Knoop hardness analysis. All patterns were included in plastic flasks especially designed for microwave irradiation. The lower half of each flask was completely filled with type III dental stone (Herodent ${ }^{\circledR}$, Vigodent ${ }^{\circledR}$, Rio de Janeiro, Brazil), whose surface was flattened with 320- and $400-\mu \mathrm{m}$ grit silicon carbide paper discs after the setting reaction. A thin film of petroleum jelly was applied, and the silicone patterns were positioned on the stone surface. Additional dental stone filled the upper half of the flask, which was opened after complete setting under compression ( 0.5 ton), and the silicone molds removed, inspecting the cavities for integrity. All molds were washed with water and neutral detergent, and coated with a separating medium (Al-Cote ${ }^{\circledR}$, Dentsply ${ }^{\circledR}$, Rio de Janeiro, Brazil).

\section{Specimen preparation}

A microwave-cured acrylic resin (Acron ${ }^{\mathrm{TM}} \mathrm{MC}$ ) was used to make the samples in this study, following the manufacturer's instructions. A mix of $30 \mathrm{cc}$ of powder and $9 \mathrm{cc}$ of liquid was prepared and left to reach the dough phase at room temperature (approximately $23^{\circ} \mathrm{C}$ ). After filling the molds with the dough, the flasks were fitted and pressed together (1.25 ton) in a hydraulic bench press for 30 minutes before polymerization.

There were 4 experimental groups in this study, according to the number of flasks for the polymerization process. Each group comprised 24 samples: Group 1 - one flask; Group 2 - two flasks; Group 3 - four flasks and Group 4 - six flasks. Each group had to provide 12 samples for the monomer release and porosity test and another 12 samples for the hardness test. That way, G1 (one flask) had to be processed four times, because each flask had 6 samples, according to Figure 1; G2 (two flasks) had to be processed twice, because each flask had 12 samples; G3 (4 flasks) had a total of 24 samples (12 samples for monomer and porosity analyses and 12 for hardness analysis); and G4 (six flasks) had a total of 36 samples (12 for monomer and porosity analyses and 12 for hardness randomly selected, and the rest discarded).

At first, all groups were irradiated in a microwave oven (Continental AW-42, Manaus, Brazil) for 3.0 minutes at $450 \mathrm{~W}$, allowing the cooling of the flasks at room temperature after irradiation. The monomer release analysis revealed that Groups 2,

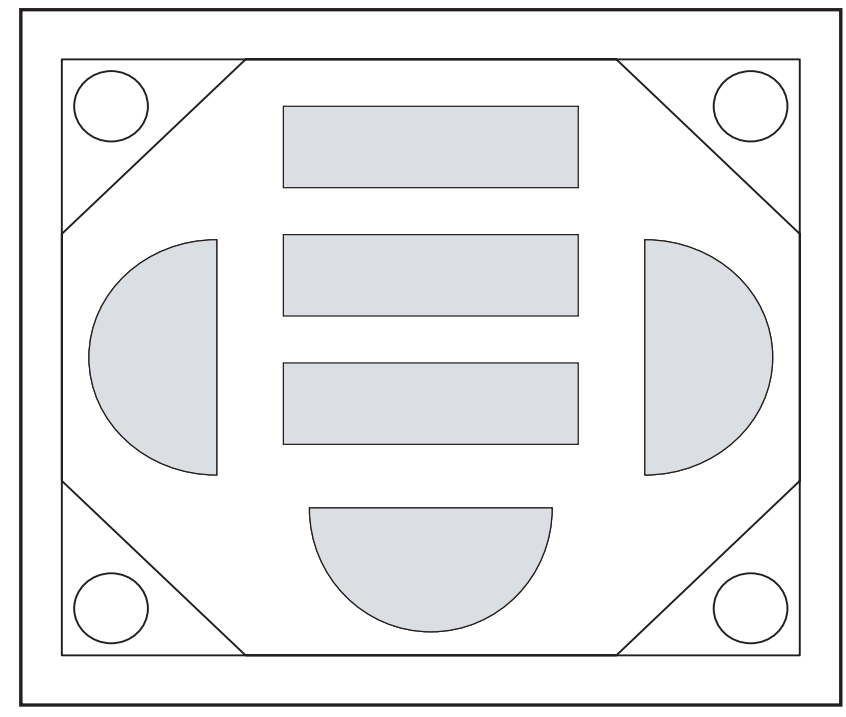

FIGURE 1 - Samples inside the flask. 
Botega DM, Machado TS, Nunes de Mello JA, Rodrigues Garcia RCM, Del Bel Cury AA. Polymerization time for a microwave-cured acrylic resin with multiple flasks. Braz Oral Res 2004;18(1):23-8.

3 , and 4 had to be processed with additional time, until the level of monomer release was similar to that of the control group (Group 1).

After removing the flasks, all specimens were trimmed with 320-, 400-, and 600-grit sandpaper in a polishing machine (Arotec, model APL-4, São Paulo, Brazil) under refrigeration. Samples for the hardness test were further finished with 1,200-grit sandpaper. After finishing and polishing procedures, all samples were cleaned in distilled water for 2 minutes in an ultrasound bath (Thorton, model T7, Inpec Eletrônica Ltda., São Paulo, Brazil).

\section{Analysis of monomer release in water}

The residual monomer determination was assayed according to the modified method of Lamb et al. ${ }^{11}$ (1982). The specimens were put in glass tubes containing $6.0 \mathrm{ml}$ of deionized water, which were closed with parafilm and stored at $37 \pm 2{ }^{\circ} \mathrm{C}$. The water was changed daily, and the monomer release was analyzed at $206 \mathrm{~nm}$ using a Beckman DU-70 spectrophotometer. Calibrations were made daily with standard solutions of 1.178 to $9.430 \mu \mathrm{g}$ of methylmethacrylate per $\mathrm{ml}$. The standards were prepared daily from a $1 \%$ solution of methylmethacrylate, and the absorbencies were read every 24 hours during a 144-hour period of analysis ${ }^{7}$. The water had to fill the tube completely because monomer is sensitive to oxygen ${ }^{15,18}$. The size of the specimens was measured, and the results were expressed in $\mu \mathrm{g}$ of monomer released per $\mathrm{cm}^{2}$ of sample area. In Groups 2, 3, and 4, if the amount of monomer was greater than the level in Group 1, the polymerization time was increased and the monomer release was analyzed again. This procedure was repeated until the amount of monomer release was similar for all groups.

\section{Knoop hardness test}

Hardness tests were performed using a hardness tester (Shimadzu HMV-2000, Shimadzu Corp., Kyoto, Japan) equipped with a Knoop diamond indenter. A 25-g load was applied for 5 seconds. Ten penetrations were obtained for each specimen, and the average hardness was calculated. The Knoop hardness test was conducted only after establishing the correct time of polymerization for each group by monomer release analysis.

\section{Porosity test}

Specimens were immersed in a solution of black ink for 30 minutes, washed for 10 seconds, and dried with absorbent paper. A surface area of $31 \mathrm{~mm}^{2}$ was delimited in the center of each specimen and observed under $100 \mathrm{X}$ magnification in a microscope (Shimadzu HMV-2000). The number of pores per area was determined for each specimen, and a score value was calculated for each group, as follows ${ }^{13,14}$ : number of pores $<30=$ light (L); number of pores between 30 and $70=$ moderate $(\mathrm{M})$; and number of pores $>70=$ heavy $(\mathrm{H})$.

\section{Statistical analysis}

Knoop hardness data were analyzed by analysis of variance (ANOVA) and Student's t-test. Monomer release data were analyzed by KruskalWallis test. Tests were performed at a confidence level of $95 \%$.

\section{RESULTS \\ Monomer release analysis}

The results of daily monomer release in water are shown in Table 1.

Considering that monomer release is an indicator of the acrylic resin polymerization level, and that there was a significant difference between

TABLE 1 - Means and standard deviations of the levels of monomer release in water $\left(\mu \mathrm{g} / \mathrm{cm}^{2}\right)$ in the $1^{\text {st }}$ phase.

\begin{tabular}{c|c|c|r|r}
\hline \hline \multirow{2}{*}{ Time } & Group 1 & Group 2 & Group 3 & Group 4 \\
& $3 \mathrm{~min} / 450 \mathrm{~W}$ & $3 \mathrm{~min} / 450 \mathrm{~W}$ & $3 \mathrm{~min} / 450 \mathrm{~W}$ & $3 \mathrm{~min} / 450 \mathrm{~W}$ \\
\hline $24 \mathrm{~h}$ & $4.15 \pm 3.37 \mathrm{~A}$ & $82.10 \pm 39.46 \mathrm{~B}$ & $532.78 \pm 126.86 \mathrm{C}$ & $1,356.17 \pm 525.35 \mathrm{D}$ \\
\hline $48 \mathrm{~h}$ & $1.51 \pm 1.47 \mathrm{~A}$ & $19.80 \pm 11.49 \mathrm{~B}$ & $45.58 \pm 82.45 \mathrm{C}$ & $440.46 \pm 85.12 \mathrm{D}$ \\
\hline $72 \mathrm{~h}$ & $1.01 \pm 0.83 \mathrm{~A}$ & $32.42 \pm 12.05 \mathrm{~B}$ & $110.72 \pm 29.37 \mathrm{C}$ & $140.02 \pm 42.77 \mathrm{C}$ \\
\hline $96 \mathrm{~h}$ & $0.72 \pm 0.64 \mathrm{~A}$ & $9.36 \pm 4.84 \mathrm{~B}$ & $59.83 \pm 19.56 \mathrm{C}$ & $77.76 \pm 12.41 \mathrm{D}$ \\
\hline $120 \mathrm{~h}$ & $0.57 \pm 0.49 \mathrm{~A}$ & $7.11 \pm 3.54 \mathrm{~B}$ & $51.70 \pm 11.62 \mathrm{C}$ & $48.46 \pm$ \\
\hline $144 \mathrm{~h}$ & $0.49 \pm 0.42 \mathrm{~A}$ & $6.20 \pm 2.19 \mathrm{~B}$ & $36.16 \pm 5.83 \mathrm{C}$ & $36.34 \pm$ \\
\hline \hline
\end{tabular}

Means followed by different letters differ from each other ( $<0.05$, Kruskal-Wallis test). 
Botega DM, Machado TS, Nunes de Mello JA, Rodrigues Garcia RCM, Del Bel Cury AA. Polymerization time for a microwave-cured acrylic resin with multiple flasks. Braz Oral Res 2004;18(1):23-8.

Group 1 and the others, a second phase was performed using 4.5, 6.0, and 7.5 minutes for Groups 2,3 , and 4, respectively. Results indicated that Group 2 showed monomer release amounts similar to amounts of the control group, but the monomer levels in Groups 3 and 4 were higher. For this reason, Groups 3 and 4 received irradiation for 7 and 10 minutes, respectively, always with $450 \mathrm{~W}$ of power (third phase). The results of this third phase showed that Groups 3 and 4 did not reach values of monomer release similar to values of the control group. Finally, Groups 3 and 4 received irradiation for 8.5 and 13.0 minutes, respectively, always with $450 \mathrm{~W}$ of power (fourth phase). Results of the fourth phase showed that Groups 3 and 4 reached values of monomer release similar to values of the control group. After the four polymerization phases, all groups showed similar quantities of monomer release (Table 2).

\section{Knoop hardness test}

Knoop hardness results are shown in Table 3. No statistical differences between the four groups were found. Simultaneous polymerization of 2 , 4 or 6 flasks, following the times established by evaluation of monomer release in water, does not interfere with Knoop hardness properties.

\section{Porosity test}

Porosity test results are shown in Table 4. Porosity did not increase in the groups with more than one flask in the microwave oven.

\section{DISCUSSION}

The objective of simultaneous microwave polymerization of several flasks is to save time and

TABLE 2 - Means and standard deviations of the levels of monomer release in water $\left(\mu \mathrm{g} / \mathrm{cm}^{2}\right)$ after adjustment of polymerization time for Groups 2, 3, and 4.

\begin{tabular}{r|c|c|c|c}
\hline \hline Time & $\begin{array}{c}\text { Group 1 } \\
\text { min/450 }\end{array}$ & $\begin{array}{c}\text { Group 2 } \\
4.5 \min / 450 \mathrm{~W}\end{array}$ & $\begin{array}{c}\text { Group 3 } \\
8.5 \min / 450 \mathrm{~W}\end{array}$ & $\begin{array}{c}\text { Group 4 } \\
13 \min / 450 \mathrm{~W}\end{array}$ \\
\hline $24 \mathrm{~h}$ & $4.42 \pm 2.81 \mathrm{~A}$ & $3.06 \pm 2.28 \mathrm{~A}$ & $5.27 \pm 5.02 \mathrm{~A}$ & $4.70 \pm 5.31 \mathrm{~A}$ \\
\hline $48 \mathrm{~h}$ & $2.73 \pm 1.16 \mathrm{~A}$ & $1.07 \pm 0.88 \mathrm{~A}$ & $1.36 \pm 1.2 \mathrm{~A}$ & $1.05 \pm 1.3 \mathrm{~A}$ \\
\hline $72 \mathrm{~h}$ & $1.37 \pm 0.82 \mathrm{~A}$ & $0.51 \pm 0.32 \mathrm{~A}$ & $0.70 \pm 0.65 \mathrm{~A}$ & $0.59 \pm 0.61 \mathrm{~A}$ \\
\hline $96 \mathrm{~h}$ & $0.92 \pm 0.73 \mathrm{~A}$ & $0.59 \pm 0.59 \mathrm{~A}$ & $0.45 \pm 0.40 \mathrm{~A}$ & $0.37 \pm 0.35 \mathrm{~A}$ \\
\hline $120 \mathrm{~h}$ & $0.52 \pm 0.37 \mathrm{~A}$ & $0.41 \pm 0.46 \mathrm{~A}$ & $0.44 \pm 0.40 \mathrm{~A}$ & $0.36 \pm 0.32 \mathrm{~A}$ \\
\hline $144 \mathrm{~h}$ & $0.45 \pm 0.36 \mathrm{~A}$ & $0.32 \pm 0.40 \mathrm{~A}$ & $0.31 \pm 0.25 \mathrm{~A}$ & $0.27 \pm 0.23 \mathrm{~A}$ \\
\hline \hline
\end{tabular}

Means followed by the same letter between groups do not differ from each other ( $p>0.05$, Kruskal-Wallis test).

TABLE 3 - Means and standard deviations of Knoop hardness.

\begin{tabular}{c|c|c|c}
\hline \hline Group 1 & Group 2 & Group 3 & Group 4 \\
$3 \mathrm{~min} / 450 \mathrm{~W}$ & $4.5 \mathrm{~min} / 450 \mathrm{~W}$ & $8.5 \mathrm{~min} / 450 \mathrm{~W}$ & $13 \mathrm{~min} / 450 \mathrm{~W}$ \\
\hline $20.75 \pm 1.29 \mathrm{~A}$ & $20.64 \pm 1.40 \mathrm{~A}$ & $21.46 \pm 1.14 \mathrm{~A}$ & $20.00 \pm 1.23 \mathrm{~A}$ \\
\hline \hline
\end{tabular}

Means followed by the same letter do not differ from each other ( $p>0.05$, Student's $t$-test).

TABLE 4 - Quantity of pores and score of each sample.

\begin{tabular}{c|c|c|c|c}
\hline \hline \multirow{2}{*}{ Specimen } & $\begin{array}{c}\text { Group } 1 \\
3 \mathrm{~min} / 450 \mathrm{~W}\end{array}$ & $\begin{array}{c}\text { Group 2 } \\
4.5 \mathrm{~min} / 450 \mathrm{~W}\end{array}$ & $\begin{array}{c}\text { Group 3 } \\
8.5 \mathrm{~min} / 450 \mathrm{~W}\end{array}$ & $\begin{array}{c}\text { Group 4 } \\
\text { min } / 450 \mathrm{~W}\end{array}$ \\
\hline 1 & $29(\mathrm{~L})$ & $26(\mathrm{~L})$ & $18(\mathrm{~L})$ & $18(\mathrm{~L})$ \\
\hline 2 & $14(\mathrm{~L})$ & $19(\mathrm{~L})$ & $18(\mathrm{~L})$ & $13(\mathrm{~L})$ \\
\hline 3 & $15(\mathrm{~L})$ & $24(\mathrm{~L})$ & $22(\mathrm{~L})$ & $16(\mathrm{~L})$ \\
\hline 4 & $14(\mathrm{~L})$ & $14(\mathrm{~L})$ & $8(\mathrm{~L})$ & $13(\mathrm{~L})$ \\
\hline 5 & $31(\mathrm{M})$ & $5(\mathrm{~L})$ & $22(\mathrm{~L})$ & $8(\mathrm{~L})$ \\
\hline 6 & $17(\mathrm{~L})$ & $15(\mathrm{~L})$ & $17(\mathrm{~L})$ & $12(\mathrm{~L})$ \\
\hline \hline
\end{tabular}

L: light; M: moderate. 
Botega DM, Machado TS, Nunes de Mello JA, Rodrigues Garcia RCM, Del Bel Cury AA. Polymerization time for a microwave-cured acrylic resin with multiple flasks. Braz Oral Res 2004;18(1):23-8.

simplify laboratory work. However, it is important to know how much this method may interfere in acrylic resin properties.

One method to verify the level of polymerization is to measure the quantity of residual monomer released in water. The technique adopted to evaluate residual monomer release in this study has been used previously by Del Bel Cury et al. ${ }^{7}$ (2001). In general, certain factors might affect monomer release results, such as evaporation of Methylmethacrylate during grinding of the specimens ${ }^{15}$, thickness of the polymerized specimen, and mixing ratio of powder and liquid ${ }^{10}$. This study controlled these negative effects by using a standardized grinding-time ( $6 \mathrm{~min})$, sample thickness $(2.5 \mathrm{~mm})$, and powder/liquid ratio.

Comparing the surface texture of resin cured in the first phase, Groups 3 and 4 exhibited softened surface aspect and high levels of monomer release (Table 1). Group 2 also had higher levels of monomer release compared to the control group. Therefore, the polymerization time applied in the first phase was not enough for complete polymerization of Groups 2, 3, and 4.

The quantity of microwave emission can be controlled by increasing the oven power or increasing the time of polymerization. Levin et al. ${ }^{12}$ (1989) showed that polymerization with less porosity occurred when using low power with increased time of polymerization. In this study, we decided to use additional time of polymerization with no change in oven power.

Similar results for monomer release were observed for all groups with polymerization times of 3.0, 4.5, 8.5 and 13.0 minutes for $1,2,4$ and 6 flasks, respectively, which showed a positive relation between resin volume and time of polymerization. Therefore, we can derive a validated equation to obtain the necessary polymerization time for simultaneous flask processing, where $70 \%$ of the time for one flask is multiplied by the number of flasks in the oven:

Time $=70 \%$ of the time for 1 flask $\times$ number of flasks

After adjusting the polymerization time for more than one flask, similar levels of monomer release were observed in all groups. Knoop hardness results showed no difference between groups with the correct time for several flasks (Graph 1).

There is a negative relation between the level of residual monomer and Knoop hardness as seen by Braun et al..$^{5}$ (1998). Thus this test confirmed the efficacy of the polymerization technique with

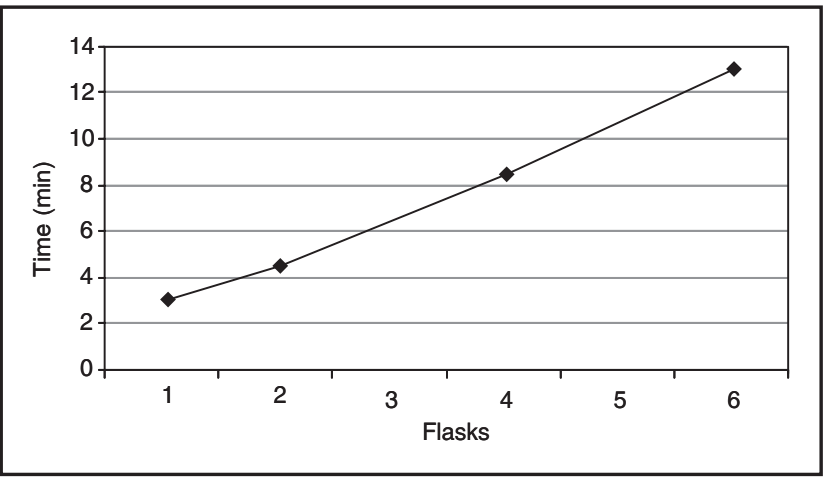

GRAPH 1 - Number of flasks versus polymerization time.

more than one flask in the oven.

Regardless of the group, residual monomer contents detected in the first 24 hours of analysis were higher than those found in the subsequent days and decreased with time. The monomer levels measured in this study support the results of earlier investigations ${ }^{4,18}$. The decrease in the daily release of monomer occurred as a result of the monomer diffusion in water and by continuous polymerization promoted by the active radicals found in the polymer chains $s^{4,5,11,18}$. After 48 hours, the content of monomer release was very low. Due to the toxicity of methylmethacrylate ${ }^{17,18}$, this finding suggests that prostheses or orthodontic appliances should be soaked in water for at least 48 hours before delivery.

Likewise, porosity was not statistically different among groups, which can be explained by a similar and efficient diffusion of heat through the surrounding materials (e.g., dental stone and silicone), avoiding exothermic heat production during polymerization $^{7}$.

The American Dental Association specification for porosity of denture base polymers states: "There shall be no bubbles or voids when viewed without magnification". The samples from all groups showed no external porosity when viewed without magnification. These results corroborate data presented by some authors ${ }^{3,9,13}$, which found no statistical difference when $3.0 \mathrm{~mm}$ thickness was used, at different polymerization cycles. These pores were small and found in all samples ${ }^{1,3,9}$.

\section{CONCLUSION}

This study suggests that the number of flasks inside the microwave oven does not interfere with the polymerization of acrylic resin if the polymerization time is adjusted to the number of flasks. 
Botega DM, Machado TS, Nunes de Mello JA, Rodrigues Garcia RCM, Del Bel Cury AA. Polymerization time for a microwave-cured acrylic resin with multiple flasks. Braz Oral Res 2004;18(1):23-8.

With setting power at $450 \mathrm{~W}, 4.5$ minutes are necessary for complete polymerization of 2 flasks, 8.5 minutes for 4 flasks, and 13 minutes for 6 flasks.

\section{REFERENCES}

1. Al Doori D, Huggett R, Bates JF, Brooks SC. A comparison of denture base acrylic resins polymerised by microwave irradiation and by conventional water bath curing systems. Dent Mater 1988;4:25-32.

2. Anusavice KJ. Phillips' science of dental materials. $10^{\text {th }}$ ed. Philadelphia: WB Saunders; 1996.

3. Bafile M, Graser GN, Myers ML, Li EK. Porosity of denture resin cured by microwave energy. J Prosthet Dent 1991;66:269-74.

4. Bartoloni JA, Murchison DF, Wofford DT, Sarkar NK. Degree of conversion in denture base materials for varied polymerization techniques. J Oral Rehabil 2000;27:48893.

5. Braun KO, Del Bel Cury AA, Cury JA. Use of microwave energy for processing acrylic resin near metal. Rev Odontol Univ São Paulo 1998;12:173-80.

6. de Clerck JP. Microwave polymerization of acrylic resins used in dental prosthesis. J Prosthet Dent 1987;57:6508.

7. Del Bel Cury AA, Rached RN, Ganzarolli SM. Microwavecured acrylic resins and silicone-gypsum molding technique. J Oral Rehabil 2001;28:433-8.

8. Harrison A, Huggett R. Effect of the curing cycle on residual monomer levels of acrylic resin denture base polymers. J Dent 1992;20:370-4.

9. Ilbay SG, Güvener S, Alkumru HN. Processing dentures using a microwave technique. J Oral Rehabil 1994;21:1039.

10. Jerolimov V, Huggett R, Brooks SC, Bates JF. The effect of

\section{ACKNOWLEDGEMENT}

Supported by The State of São Paulo Research Foundation (FAPESP 98/05560-2).

variations in the polymer/monomer mixing ratios on residual monomer levels and flexural properties of denture base materials. Quintessence Dent Technol 1985;9:4314.

11. Lamb DJ, Ellis B, Priestley D. Loss into water of residual monomer from autopolymerising dental acrylic resin. Biomaterials 1982;3:155-9.

12. Levin B, Sanders JL, Reitz PV. The use of microwave energy for processing acrylic resins. J Prosthet Dent 1989;61:381-3.

13. Reitz PV, Sanders JL, Levin B. The curing of denture acrylic resins by microwave energy. Physical properties. Quintessence Int 1985;16:547-51.

14. Rodrigues Garcia RCM, Del Bel Cury AA. Accuracy and porosity of denture bases submitted to two polymerization cycles. Indian J Dent Res 1996;7:122-6.

15. Sadamori S, Shigeto N, Hamada T, Okuda K. A method of determining residual monomer in acrylic resin using methyl ethyl ketone. Aust Dent J 1990;35:509-13.

16. Sanders JL, Levin B, Reitz PV. Comparison of the adaptation of acrylic resin cured by microwave energy and conventional water bath. Quintessence Int 1991;22:181-6.

17. Sheridan PJ, Koka S, Ewoldsen NO, Lefebvre CA, Lavin MT. Cytotoxicity of denture base resins. Int J Prosthodont 1997;10:73-7.

18. Vallittu PK, Miettinen V, Alakuijala P. Residual monomer content and its release into water from denture base materials. Dent Mater 1995;11:338-42. 